\title{
Educação pela amorosidade: uma alternativa para a escola pública no Amapá?
}

\author{
Education for love: an alternative for the public school in Amapá? \\ Éducation pour l'amour: une alternative pour l'école publique à Amapá?
}

João Wilson Savino Carvalho ${ }^{2}$

Universidade Federal do Amapá

Geraldo Inácio Filho²

Universidade Federal de Uberlândia

Resumo: Trata-se de um estudo que tem fundamento no pensamento dialético de Maria Cecília Minayo e categoria de análise as representações da "baixada", tal como projetadas na linguagem dos alunos das escolas públicas localizadas no seu entorno, e que analisa o trabalho e as perspectivas do Grupo de Educação Continuada, uma equipe de professores que, com base nas formulações de Humberto Maturana e no pensamento complexo, vem desenvolvendo práticas educativas de entrelaçamento da dimensão amorosa e cognitiva nas escolas públicas do Amapá. O estudo foca principalmente as possibilidades dessa prática na abordagem da sociabilidade violenta na escola pública do Amapá, a partir do material didático produzido pelo Grupo e dos resultados de sua aplicação em escolas públicas do Estado.

Palavras-chave: Educação Continuada. Sociabilidade Violenta. Escola pública.

Abstract: This is a study that is based on dialectical thinking of Theoretical Maria Cecilia Minayo and analysis category representations of "baixada" designed in the language of public school students located around them, and analyzing the work of the Group Continuing Education, a team of teachers supported by the Education Department of the State of Amapá that, based on the formulations Humbeto Maturana and complex thought, is developing practices intertwining of love and cognitive dimension in the public schools of Amapá. The study focuses mainly on the possibilities of this practice in addressing violent sociability in the public school of Amapá, from the didactic material produced by the Group and the results of its application in the public schools of the state of Amapá.

Keywords: Continuing Education. Sociability violent. Public school.

Résumé: Il s'agit d'une étude basée sur la pensée dialectique de Maria Cecilia Minayo et la catégorie d'analyse des représentations de la "bajada", projetées dans la langue des élèves des écoles publiques situées dans son environnement, et qui analyse du Groupe de l'éducation permanente, une équipe d'enseignants qui, à partir des formulations de Humberto Maturana et de la pensée complexe, a développé des pratiques pédagogiques combinant amour et dimension cognitive dans les écoles publiques d'Amapá. L'étude porte principalement sur les

\footnotetext{
${ }^{1}$ Professor de Filosofia Geral e Jurídica da Universidade Federal do Amapá - UNIFAP, Macapá (AP). Doutor em Educação pelo PPGED/Faced/UFU.E-mail: wilsoncarvalho@unifap.br.

2 Professor do Programa de Pós-Graduação em Educação da Universidade Federal de Uberlândia PPGED/Faced/UFU. Pós-Doutorado na Universidade de Lisboa. Pesquisador CNPQ, Uberlândia (MG). Email: geraldoinacio@terra.com.br
} 
possibilités de cette pratique dans l'approche de la sociabilité violente à l'école publique d'Amapá, sur la base du matériel didactique produit par le Groupe et des résultats de son application dans les écoles publiques.

Mots-clés: Éducation permanente. Sociabilité violente. École publique.

\section{Introdução.}

A simples existência de uma prática educacional singular construída por iniciativa de um grupo de professores amapaenses "do chão da escola”, para utilizar uma expressão bem cara ao professor Carlos Lucena (2011), ou seja, educadores com longa experiência na sala de aula da escola pública e no enfrentamento de suas mazelas, pautada em uma epistemologia critica, criativa e pluralista, e que tem se mostrado apropriada ao trato com a questão da violência e suas consequências no espaço da escola pública do Amapá, já seria motivação suficiente para que merecesse tal iniciativa cuidadoso estudo e acompanhamento.

Mas, na verdade, a principal motivação para o presente texto, é a calamitosa situação da escola pública no Amapá, e a possibilidade da compreensão desse aparente caos a partir do desvio dos princípios básicos tradicionais de organização das questões psicossociais no interior da escola, em função do reflexo da desagregação das relações sociais no âmbito da comunidade, pela adesão a um tipo específico de organização social, a sociabilidade violenta.

O fato é que o modelo do garoto da escola pública não é mais o pai, o professor, ou o piloto de avião como era dantes, mas sim o soldado do tráfico, o portador de uma arma que o garoto só vê em filmes; o atirador de elite que protege o rei do narcotráfico da favela onde o garoto mora, e por conta disso tem inúmeras amantes e benesses condizentes com o seu status de elemento imprescindível na pirâmide do poder; ou, para uns, os mais ambiciosos, e futuros líderes no crime, o próprio "rei da baixada”.

Nas maiores cidades do Amapá o fenômeno do crescimento das "baixadas" é relativamente recente, mas impressiona pelo alto índice de pobreza e violência. A "baixada” é geralmente uma área de ressaca, de ocupação recente, basicamente por migrantes, mediante interesses políticos, sem qualquer planificação urbana, e que no imaginário amapaense ocupa o lugar do morro carioca. Muitas das baixadas de Macapá e Santana são identificadas pelo nome do criminoso que domina o lugar. 
Poderíamos discutir indefinidamente esse fenômeno como a formação de uma subcultura criada pela inversão dos valores sociais contraditórios e insustentáveis, ou como uma reação vaga e indiferenciada à sociedade de consumo, e que até poderia ser vista como uma contracultura, ou, até mesmo demonstrar que é o fenômeno mero reflexo da exploração capitalista.

Entretanto, como queremos discutir educação no espaço concreto da escola pública, preferimos analisar um caso real, uma proposta desenvolvida institucionalmente por um grupo de professores denominado Grupo de Educação Continuada, originado no antigo Instituto de Educação do Amapá, e após a extinção dessa escola, estabelecido como um Núcleo de Projetos, no âmbito da Secretaria de Educação do Governo do Estado do Amapá, como uma forma de abordagem do problema da violência nas escolas públicas do Amapá e com o objetivo de prestar assessoria técnica às escolas públicas do Amapá, distribuindo material de apoio e atuar permanentemente na preparação de gestores e professores do ensino básico para o enfrentamento das mais diversas questões que surgem no quotidiano escolar, para o qual não foram preparados em sua formação docente.

Na prática, o trabalho desse grupo é, em apertada síntese, desenvolver de forma sistemática a dimensão amorosa da educação na escola pública, atuando diretamente em espaços concretos e problemáticos, aplicando uma metodologia pautada no pensamento complexo e na pedagogia libertadora. E é assim que o projeto é estendido às escolas públicas do Estado, como uma alternativa de superação do desânimo que ora toma conta dos professores, e ao descompasso da educação pública com a realidade do mundo atual, que desgasta os educadores nas escolas e faz desmoronar todo o esforço empregado, além de aumentar enormemente os custos do sistema escolar.

Essa é, basicamente, a proposta de trabalho do Grupo de Educação Continuada, que consiste, conforme o material didático produzido pelo Grupo, numa autorreflexão sobre o entrelaçamento das dimensões amorosas e cognitivas na escola e que, na prática, se dá pela apresentação da perspectiva do grupo por meio de poesias, músicas, reflexões místicas e técnicas de relaxamento. Concomitantemente, são produzidos textos-artigos e material metodológico para uso dos professores em sala de aula, como forma de apoio ao projeto de expansão do fazer-sentir-pensar educativo nas escolas, na busca da ampliação da qualidade da vida tanto de professores como dos alunos.

Um trabalho dessa natureza envolve a reflexão filosófica em conjunto com a prática educativa dos educadores da escola pública, chamando atenção para a dimensão amorosa na 
escola, pela vivência do cuidado amoroso no diálogo, no respeito e na não-violência, buscando entrelaçar a dimensão amorosa com a dimensão cognitiva na educação escolar, visando fortalecer em cada educador a autoconstrução na amorosidade, de modo a que possa enfrentar os atuais desafios do trabalho na escola pública.

Se com essa proposta o grupo alcança uma humanização do espaço da escola pública de periferia, criando a oportunidade de mostrar uma nova perspectiva aos educadores que têm sua rotina diária em uma escola onde a violência aparentemente inexplicável se naturaliza entre a comunidade escolar (instaurando absurdos, como a escolha de diretores pelo seu porte físico), e com isso torna-os capazes de vislumbrar uma luz no fim do túnel, então, apenas por isso, já se justificaria o investimento da Secretaria de Educação do Governo do Amapá na manutenção desse projeto.

Mas como o Grupo chegou a essa proposta? Qual seu nível de compromisso e vivência com o problema da sociabilidade violenta na escola pública no Estado? E quais seus resultados concretos?

Eis que é esse o objetivo do presente texto, uma análise hermenêutico-dialética da atuação do Núcleo de Formação Continuada da Secretaria de Educação do Amapá, sua proposta, seu referencial teórico, e seus resultados. Tal análise é fundamentada no pensamento de Maria Cecília Minayo, para quem a dialética é um caminho do pensamento e a pesquisa um artesanato intelectual, e tem como categoria de análise as representações sociais projetadas na fala dos atores que vivenciam o problema.

\section{A origem e os objetivos do Grupo de Educação Continuada.}

O Grupo de Educação Continuada surgiu como um prolongamento da cultura escolar de formação solidária em serviço e trabalho coletivo que floresceu no antigo Instituto de Educação do Amapá - IETA, formada de representações sociais resultantes de um longo processo de amadurecimento do corpo técnico e docente em práticas pedagógicas concretas, que, ante a extinção iminente da escola, instituiu, ainda em 2001, um grupo formado basicamente com os professores interessados na manutenção dessa cultura escolar e na sua extensão para as demais escolas públicas do Estado (SOUZA, 2001).

Ou seja, um grupo de educadores de longa experiência em sala de aula, que assumiu o encargo de pensar-fazer a educação na escola, e que, diante do fracasso de sua luta e da inevitabilidade da extinção dos Institutos de Educação, partiu para a preservação dos valores 
e da cultura escolar que distinguiu e deu identidade a sua escola, apresentando-a como solução aos graves problemas de falta de sentido da prática educativa na escola pública do Amapá, refletidos hoje no desinteresse profissional dos professores e nos altos índices de reprovação e abandono, na violência gratuita dentro das escolas e nos incontáveis afastamentos de professores do trabalho, por traumas ou problemas de saúde causados pelo estresse diário a que são submetidos, enfim, no desperdício de recursos públicos no ensino público básico e que são atacados por meio de políticas públicas paliativas, como a imposição de cotas no ensino superior para alunos oriundos de escolas públicas, sem a necessária atuação na melhoria da qualidade do ensino básico.

E talvez seja esse o grande valor da proposta do Grupo, a sua origem em uma longa experiência em um modelo de escola pública reconhecida pela luta que manteve em prol de uma autonomia pedagógica ao longo de toda a sua vida:

Tudo isso demonstra que no IETA foi engendrada uma cultura escolar singular e própria, onde a construção de um saber no campo da didática das disciplinas instrumentais para as séries iniciais do ensino fundamental constituía o carro-chefe, e a relação administração-corpo técnico-docente e aluno se constituía a partir dessa perspectiva didática. Tal cultura ultrapassou os momentos políticos do Amapá, os modismos pedagógicos e a predominância de linhas do pensamento pedagógico que se sucederam ao longo de sua trajetória, mantendo sempre uma perspectiva de busca de excelência na formação de professores dos anos iniciais em nível de segundo grau. (CARVALHO, 2012, p.21).

Em 2005 o Grupo de Educação Continuada passou a integrar o Núcleo de Formação Continuada, funcionando em um prédio da Secretaria de Educação situado na Praça Floriano Peixoto (que é muito utilizada para apresentações da concepção de educação continuada em espaço aberto), próximo ao centro comercial de Macapá, onde passou a cumprir um cronograma de trabalho nas escolas públicas da capital e do interior do Estado do Amapá, apresentando ainda, nos espaços dessa programação, a linha de trabalho do grupo para outros segmentos e instâncias da Secretaria de Educação do Estado.

Pela forma atrativa de apresentação vivenciada, o Grupo conseguiu levar a sua proposta não apenas às escolas públicas, mas também às praças públicas, onde sua apresentação desperta a curiosidade dos passantes e o interesse em entender "o que é aquilo", onde professores representam performances nos gramados da praça, atiram aviõezinhos de papel com mensagens educativas e expõem enormes painéis, presos por cordames de uma árvore a outra da praça. 
Conforme os textos utilizados pelo Grupo, os objetivos de um trabalho dessa natureza são principalmente: estudar-refletir as bases epistemológicas e ontológicas do fazer-sentirpensar educativo com os educadores da escola abordada; tornar visível a dimensão cuidanteamorosa nas relações na escola; vivenciar o cuidado amoroso no diálogo, no respeito e na nãoviolência; entrelaçar a dimensão cuidante-amorosa com a dimensão cognitiva; fortalecer em cada educador a autoconstrução na amorosidade.

Os meios para alcançar esse objetivo são a vivência do próprio encontro no projeto; a entrega das cartilhas de poesia, de história, de teatro, de música, de filmes, etc., que são produzidas pelo próprio grupo, além do caderno de contação de histórias. E é assim que o projeto é levado às escolas, como uma alternativa de superação do desânimo e descompasso com a realidade do mundo atual, que desgasta os educadores nas salas de aula e faz desmoronar todo o esforço empregado, desperdiçando os recursos do sistema escolar.

Os resultados buscados são a superação do estresse na escola, a convivência pacífica na solidariedade, a criação de um ambiente escolar acolhedor, o aumento da qualidade de vida, enfim, para os componentes do Grupo, tudo o que sonhavam para a sua escola e que desejavam expandir para todas as escolas públicas do Amapá.

Na verdade, o Grupo Educação Continuada surgiu em um momento crítico, quando o Instituto de Educação do Amapá estava decididamente extinto, e o grupo de professores conhecidos como o "Grupo do IETA", compreendendo que só lhes restava disseminar a cultura escolar de autonomia e liberdade que desenvolviam no Instituto de Educação para todas as escolas da rede estadual, dirigiram-se ao governador do Estado, à Secretária de Educação, procurando apoio para a sua causa em educadores que tinham passado pelo Instituto de Educação e que eram considerados de renome no Amapá.

A empreitada acabou por não encontrar rejeição, até porque esse grupo era constituído de educadores com reconhecimento na comunidade, e que traziam a ideia de uma educação permanente e continuada, uma formação em serviço, para enfrentar o desalento que invade a educação brasileira em todos os aspectos, com as consequências mais funestas possíveis, panorama que é visível nos noticiários que a mídia propala como o ponto do caminho em que não há retorno.

Trabalhamos aqui com um processo de educação permanente com todos os profissionais de educação, não só com professores, construindo e reconstruindo concepções de educação. Educação, não capacitação... Mas tivemos problemas logo no começo, porque alguns professores ficaram com medo de perder a regência de classe, mas a Secretária, garantiu que não teríamos essa perda, até porque estávamos nas escolas. Isso fortaleceu o grupo. Fomos para muitas localidades do interior, falamos até com 
vereadores e estamos escrevendo um livro, registrando toda a nossa experiência. Só numa escola de Macapá, D. José Maritano, ficamos três anos, indo à escola três vezes por semana, porque lá nos desafiaram a trabalhar com um grupo que era chamado "os perdidos da escola", porque todos já tinham desvanecido de conseguir que estudassem, passassem de ano ou apresentasse um comportamento razoável dentro da escola. Com a nossa linha de trabalho vencemos esse desafio, e eu tenho essa experiência devidamente registrada. (Profa. Maria José Silva - Núcleo de Formação Continuada, in CARVALHO, 2012).

E, realmente, a tarefa que se propõe o Grupo, de falar da dimensão amorosa na escola, não é fácil, mas pode representar uma alternativa de solução para um dos mais graves problemas da escola pública no Amapá, onde um número considerável de professores encontrase afastado de sala de aula por problemas psíquicos. Para um dos os componentes do Grupo, por espantoso que esse número pareça, "não há o que estranhar, já que, com uma educação impositiva, falando 'para' e não 'com' uma clientela que está na era digital, enquanto o professor em sala de aula ainda está mandando o aluno escrever em um caderno, só tem como resultado o caos" (SILVA, 2011, p.2). Para o grupo, a solução é chegar ao coração dos alunos, com projetos capazes de conquistá-los lá onde estão: “É preciso ressignificar nosso fazer pedagógico na escola ou a convivência vai ficar impossível, com os alunos na era virutal e a escola imóvel no tempo"(SILVA, 2011 , p.2).

Enfim, pode-se discordar da proposta do Grupo e até criticá-la como irrealizável em grande escala, como a da rede pública estadual do Amapá. O que não se pode negar que é a única proposta apresentada por educadores amapaenses para o enfrentamento da situação insana em que se encontram as escolas da rede pública amapaense, onde, em alguns casos, o professor necessita de apoio policial para executar seu trabalho de rotina.

\section{A sociabilidade violenta nas escolas públicas do Amapá.}

O Estado do Amapá é uma unidade federativa que apresenta uma história e uma geografia que lhe conferem singularidade em relação aos outros estados. Primeiro, por ter sido, desde 1637, a remota Capitania da Costa do Cabo Norte (Terra dos Tucujus), depois o Contestado Franco-brasileiro (1841), parte esquecida do Pará, o município de Montenegro (1900), e em 1943, Território Federal do Amapá (quando ficou conhecido como Terra do Manganês) até 1988, com a Constituição Cidadã, quando foi transformado em Estado; e, em segundo, pela posição geográfica isolada no setentrião amazônico, que the confere uma situação de quase ilha, e que o leva a procurar caminhos em outra direção, a França 
Ultramarina, a fronteira do Brasil com a Comunidade Europeia e todas as possibilidades que tal situação pode oferecer (para o bem ou para o mal).

Assim, o Amapá, no mesmo tempo que ostenta o passado glorioso de um povo que lutou, inclusive com derramamento de seu sangue, para ser brasileiro, carrega consigo também o estigma e as mazelas de ter permanecido longamente na cômoda condição de Território Federal, com uma economia dependente dos salários do grande número de funcionários federais, contribuindo para a Federação apenas com o seu rico subsolo, integrado na lógica perversa da retirada das riquezas minerais até a exaustão, que caracterizou as economias amazônicas no século XX.

Na história recente, os dois grandes grupos familiais que dominam o panorama político do Amapá apoiaram duas linhas de desenvolvimento para o Amapá: um, com base no empresariado local, tinha nas áreas de livre comércio e na expansão da oferta de emprego no setor de serviços o futuro do Estado; e o outro, com apoio na maré internacional de valorização do meio ambiente e da ecologia, propondo um plano de desenvolvimento sustentável, apostando na agregação de valor aos produtos locais em uma relação equilibrada com o meio ambiente, onde os resultados mais visíveis hoje foram a substituição da exploração predatória do palmito pela exportação do fruto da palmeira, o açaí, e a valorização da fitoterapia regional (andiroba, copaíba, barbatimão, etc.), e a maior preocupação com a biodiversidade no Estado (CARVALHO, 2012).

Paralelo a isso e fruto de uma propaganda enganosa da situação econômica do Estado, patrocinada por interesses políticos espúrios, uma desenfreada migração, vinda principalmente das áreas rurais pauperizadas do Estado do Maranhão, das devastadas ilhas do Pará situadas no estuário do Amazonas e defronte de Macapá, e das violentas e falidas cidades de garimpo do sul do Pará, inchando ao insuportável os sistemas de saúde e educação, e colocando em cheque a segurança, principalmente nos municípios de Macapá, a capital, de Santana, o porto, e Laranjal do Jari, com suas enormes favelas de palafitas, onde se alternam anualmente enchentes e incêndios, e sua endêmica prostituição infantil, favorecida pela pobreza e pela violência urbana (PORTO, 1999).

E na linha da ocupação desenfreada do espaço urbano, uma heresia ambiental, a ocupação das ressacas, áreas de alagamento sob a influência da maré que constituem todo um ecossistema complexo, e que, pela sua ligação com o Rio Amazonas, funciona como bacias de acumulação e drenagem das águas das chuvas. Essas áreas, que permanecem alagadas o ano inteiro ou apenas na época das chuvas, onde pássaros, peixes, pequenos mamíferos e insetos se 
alimentam e se reproduzem, com espécies de plantas bem típicas, como o mururé ou o buriti, têm, ainda, importante função no equilíbrio térmico da cidade, justamente por constituírem fonte de umidade e circulação do vento, amenizando o clima equatorial da região.

Como é fácil deduzir, as áreas de ressaca permeiam a cidade, de modo que as baixadas situamse bem próximo, quando não envolvem totalmente, de áreas de ocupação regular e ordenada, onde se situam escolas públicas de tradição, mas despreparadas para o atendimento da clientela oriunda da baixada.

Na baixada começam a coexistir então duas ordens: a estabelecida por lei e a outra, cujo poder cresce na mesma proporção do tamanho da baixada. De fato, quanto maior a baixada, maior o emaranhado de fios elétricos, o furto de energia, e menor a possibilidade de coibir-se a expansão das economias marginais e parasitárias, como a venda de proteção aos pequenos comerciantes e donos de botecos, a exploração de prostitutas, os desmontes de motocicletas, enfim, das atividades ilegais que vão se naturalizando para a população da baixada, à medida que seu conceito se transforma de "invasores de um espaço protegido" para "carentes" que ali residem pela falta de um planejamento e da execução de políticas públicas para a expansão organizada da cidade.

Eis que essa segunda ordem não é propriamente uma ordem, no sentido rigoroso do termo, mas uma forma de relações sociais diferente, onde o princípio básico instituinte não é a lei ou o conceito de justiça, mas sim a força. Aí a violência urbana não é mais apenas um fenômeno composto de atos de violência, cujo aumento ou diminuição pode ser medido ou combatido pelos atos individuais. Como representação de uma forma de sociabilidade, o fenômeno é muito mais grave e complexo. É o que Machado da Silva chama de sociabilidade violenta, que define como um padrão de sociabilidade que tem no uso da força não um meio, mas um princípio:

Sugere-se aqui que a representação da violência urbana reconhece um padrão específico de sociabilidade, que será chamado de sociabilidade violenta. $\mathrm{Na}$ sua descrição, é possível começar lembrando que a característica central da violência urbana é captar e expressar uma ordem social, mais do que um conjunto de comportamentos isolados. Ou seja, as ameaças à integridade física e patrimonial percebidas provêm de um complexo orgânico de práticas, e não de ações individuais. Assim, pode-se apresentar a característica mais essencial da sociabilidade violenta como a transformação da força, de meio de obtenção de interesses, no próprio princípio de regulação das relações sociais estabelecidas. (Machado da Silva, 2004, p.39). 


\section{As representações e o imaginário social da baixada.}

A representação, como produto e faculdade humana de substituir por abstrações a realidade percebida, é parte essencial do processo de cognição. Tão antiga quanto às discussões filosóficas gregas sobre a relação pensamento e linguagem, não constitui nenhuma novidade no pensamento ocidental.

Um traço de fundamental importância nas representações é o fato de constituir meios de firmar o pertencimento a um grupo social. Um indivíduo se sente negro ou branco não somente pelo tom da sua pele, mas principalmente porque tem na representação do grupo dos negros ou dos brancos uma referência.

Maria Cecília Minayo é bem direta quanto ao processo de institucionalização de representações e quanto à linguagem como o espaço privilegiado de sua manifestação:

\footnotetext{
Representações são categorias que expressam a realidade, explicam-na, justificando-a ou questionando-a. (MINAYO, 1994, p. 89).

As representações sociais se manifestam em palavras, sentimentos e condutas e se institucionalizam, portanto, podem e devem ser analisadas a partir da compreensão das estruturas e dos comportamentos sociais. Sua mediação privilegiada, porém, é a linguagem, tomada como forma de conhecimento e de interação social. (MINAYO, 1994, p. 108).
}

As representações constituem uma categoria basal em qualquer estudo do imaginário. Para Japiassu (2001), o imaginário é o conjunto de representações, crenças, desejos, sentimentos, em termos dos quais um indivíduo ou grupo vê a realidade e a si mesmo. E para Le Goff, citado por Chatier (1990), o imaginário não é um simples reflexo da realidade, à medida que as representações da realidade que o compõem constituem uma espécie de tradução mental da realidade percebida. Da mesma forma, o imaginário não é o criador da realidade, mas mantém com ela uma relação estreita e complexa, porque nela influencia continuamente.

Enfim, as representações sociais podem ser definidas como “imagens construídas sobre o real" (MINAYO, 1994, p. 108), e ainda que apareçam como elaboradas em uma mente individual, se estabelecem socialmente no espaço do grupo como saberes consensuais naquele grupo, criando referências do próprio grupo, e por isso estão relacionadas ao imaginário social de um grupo pelo aspecto simbólico a elas inerente.

É possível que exista um imaginário da baixada? E se existe, é possível captá-lo de alguma forma?

Considerando que estamos utilizando o termo "imaginário" como conjunto relativamente estável de representações simbolicamente relacionadas, podemos afirmar que 
sim, principalmente se esse imaginário é construído a partir de uma representação instituinte, aquela unifica o conjunto e lhe dá identidade.

\section{O caso do "Clênio Baixada".}

Como a baixada é um lugar tido como perigoso, feio e pobre, a princípio, não é de se esperar que alguém se sinta feliz em basear nela a sua identidade, principalmente se essa pessoa nem sequer reside lá. Entretanto, em uma aparente contradição, a identificação com a baixada pode até se apresentar vantajosa para o estudante em processo de construção de identidade e em relação ao complexo de valores que interferem nessa construção.

As situações práticas e resultados dessa proposta podem ser demonstrados em caso ocorrido em 2012, em uma escola pública do centro de Macapá: uma série de pichações ameaçadoras assinadas por um determinado "Clênio Baixada" (o nome verdadeiro foi substituído por motivos éticos) começaram a aparecer nos banheiros da escola. Não foi difícil descobrir que era o autor porque o nome próprio era real e bastante incomum para Macapá, e o garoto parecia não fazer muita questão de ocultar que era ele o "da baixada”, e até, pelo contrário, aparentava querer assumir esse apelido.

Mas o estranho nesse caso é que o garoto morava no centro, e não na "Baixada do Japonês", como seria de se esperar, já que era a que ficava mais próxima do centro, e tampouco era envolvido com gangs de adolescentes, drogas ou violência de qualquer tipo. Ele era, como muitos de sua idade, frequentador assíduo de lojas de acesso à internet, bastante inteligente, mas meio solitário e um tanto caladão. Seus pais eram pobres e não poderiam mantê-lo em uma escola particular, mas ele não passava por nenhum tipo de privação. As frases que pichava eram ferozes e antissociais. E a questão que intrigou professores e técnicos da escola: por que queria tanto ser identificado como "da baixada”?

Uma professora que se interessou pelo caso desse garoto morava, ela sim, na baixada próxima, e assim se identificando, conseguiu estabelecer um diálogo bastante aberto com o garoto, conseguindo descobrir que o avanço recente da baixada estava tomando conta dessa escola, que era anteriormente era disputada pelos alunos moradores do centro, e agora recebia grande parte de sua clientela de garotos da baixada, cuja linguagem Clênio já havia incorporado, não apenas quanto ao vocabulário, mas também quanto ao modo de falar, inclusive com o sotaque dos migrantes que compunham a maioria dos moradores dessa baixada. 
Aparentemente, o garoto estava querendo se prevenir da possibilidade de vir a sofrer bullying por parte dos garotos vindos da baixada, mas quando ele começava a declinar suas imagens da baixada (onde ele nunca tinha ido), tornava-se possível visualizar que o problema era incomparavelmente mais complexo.

Para ele a baixada era um lugar onde as regras eram bem claras. Quem tinha a força, tinha o poder sobre os outros. Quem não tinha, simplesmente obedecia e assim vivia bem. Não eram as leis, nem o conceito de justiça, ou muito menos as regras morais ou de etiqueta que regiam a vida no asfalto, que organizavam a vida na baixada. Era simplesmente a força (que às vezes se confundia com a competência para a violência - ou a lógica do pitbull).

Em compensação, quando se referia à vida no centro, demonstrava que a entendia como um estranho faz-de-conta. Sabia que existiam as leis, mas que eram cumpridas só eventualmente. Tinha certeza que a vida não era justa, já que as pessoas que não trabalhavam ganhavam mais que as que se matavam de trabalhar. Regras morais eram frustrantes, e quanto às de etiqueta, não sabia para o quê poderiam servir. Realmente, era um garoto muito inteligente.

Entretanto, como é muito comum em adolescentes, apresentava um problema complexo de autoestima, e relacionado a isso, a necessidade de integração em um grupo capaz de satisfazer essa necessidade de pertencimento a uma comunidade onde fosse possível uma ordem alternativa e mais verdadeira do que aquela que ele conhecia. A sociabilidade violenta apresentava-se, para ele, por bizarro que possa parecer, como a única alternativa de sobrevivência em um mundo absurdo, onde o que lhe era ensinado na escola, o local onde uma pessoa devia aprender, não era compatível em nada com a sua verdadeira ordem de vivência.

Até mesmo a projeção da ordem legal na baixada, a atuação da polícia na perseguição de criminosos que lá se escondiam, lhe afigurava ridícula, porque tratava os moradores todos como criminosos em potencial, e, ao mesmo tempo, pedia colaboração dos moradores sem lhes fornecer meios mínimos de defesa, já que a tal ordem desaparecia de cena tão logo o objetivo primário da intervenção era alcançado. Afinal, a polícia também era representada na baixada pelo seu poder de fogo, jamais como representante de uma ordem justa e coerente.

Não era tão estranho então que, mesmo conhecendo a baixada só pela fala de outras pessoas, quisesse para ele essa identificação. Afinal, as representações da baixada lhe garantiam algo que nunca teve no centro: identidade coerente (sensação de pertencimento a um grupo de atitude coerente com a ordem da vivência). 
Como a desse garoto, existiam inúmeras situações similares, para os quais a escola não faz o mínimo sentido. De fato, quando o garoto da baixada (ou do centro) destrói o patrimônio da escola e nada acontece, nem sequer a reposição do que foi destruído, esse garoto não sente nenhuma alteração de rotina.

Clênio recebeu atenção individualizada da professora que se interessou pelo caso, e que, de posse do material fornecido pelo Grupo de Educação Continuada, passou a demonstrar aos seus colegas professores as causas da atitude do aluno, e, ao mesmo tempo, ao aluno, a ingenuidade e a ineficácia de seu comportamento, apontando para outra forma de relacionarse com seus problemas de integração na escola, substituindo a força pela amorosidade, a frustração pela compreensão, e a angústia pela confiança, resultando essa abordagem em um relativo sucesso, considerando-se como referencial o encerramento das pichações na escola e da postura agressiva do aluno em relação aos seus professores.

\section{A base teórica da proposta do Grupo de Educação Continuada.}

O referencial teórico para o engendramento dessa proposta é principalmente o pensamento de Humberto Maturana, para quem a vida é um processo contínuo de conhecimento, e para compreendê-la, é preciso primeiro entender como conhecemos, e o que conhecemos, o que remete o problema da vida para a Teoria do Conhecimento. Aliás, para entender o pensamento de Maturana, necessário se faz estabelecer o significado de alguns conceitos básicos, por meio dos quais esse pensador articula suas principais teses. O primeiro conceito é o de autopoiese (os seres vivos são "máquinas", que se distinguem de outras - as mecânicas mesmo - por sua capacidade de autoproduzir-se). A primeira tese é a da deriva natural (a evolução das espécies ligada à forma como os seres realizam sua autopoiese, e que se conserva transgeracionalmente em um modo de vida que depende de sua história de interações).

Dai a segunda tese, ou consequência da articulação do conceito de autopoiese com a tese da deriva natural: a evolução natural do ser humano como ser vivo particular, é centrada na emoção que determina a deriva natural. Então é o amor que dá origem à convivência social e à constituição da linguagem e a todas as características que nos distinguem como seres humanos.

Um segundo conceito básico é o representacionismo cultural (somos seres culturais, e na cultura representamos o mundo), e a tese a ele relacionada é que a objetividade e a 
subjetividade, assim como o quantitativo e o qualitativo, existem em interação dialética, e assim é que são ambos indispensáveis ao conhecimento e à ciência.

O conhecimento em Maturana é definido como "uma ação efetiva, ou seja, uma efetividade operacional no domínio da existência do ser vivo. (...) Ação que permita um ser vivo continuar sua existência em um determinado meio ao fazer surgir o seu mundo" (MATURANA e VARELA, 2001, págs. 35).

$\mathrm{O}$ ato de conhecimento envolve o eu e o agir, e essa é a atitude epistemológica de Maturana : "Todo fazer é um conhecer e todo conhecer é um fazer (...) Tudo o que é dito é dito por alguém". (2001, p. 31). De mais a mais, o conhecimento é o próprio viver, "viver é conhecer, é ação efetiva no existir como ser vivo" (2001, p. 194).

\section{A prática educativa do Grupo e suas perspectivas.}

O Núcleo de Formação Continuada é a institucionalização do Grupo de Educação Continuada, que por sua vez representa uma continuidade do pensamento educativo e da cultura escolar desenvolvida no antigo Instituto de Educação do Amapá (CARVALHO, 2012), e seus objetivos já aparecem firmados na Revista Religando - O Conhecer ao Viver (SET/2007, p. 9), que são essencialmente objetivos compatíveis com o critério dialético de verdade, a práxis, porque firmam a promoção de ações educativas enraizadas na realidade social e tecnológica de hoje, visam o redirecionamento e implementação de propostas que religuem o conhecer ao viver nas redes de ensino do Estado, com base em três eixos norteadores: cidadania - democracia - desenvolvimento econômico com equidade e a serviço do social.

Ao fortalecer o desenvolvimento desses três eixos na prática docente e nos currículos escolares valorizando elementos naturais e locais disponíveis, e ao buscar na própria escola práticas alternativas para valorização do ensino, para ampliação da qualidade do ensino público, sistematizar a formação continuada dos educadores, estimular o conhecer a si próprio na relação com o outro, a reflexão sobre a própria prática, enfim, contemplar as especificidades da região dentro dessa linha de pensamento, cuja base está no título da revista editada pelo grupo: religar o conhecer ao viver, o Grupo de Educação Continuada busca um resgate da professoralidade na escola pública (BOLZAN e POWACZUCK, 2009).

Na prática, são variadas as ações desenvolvidas pelo Grupo, mas podemos exemplificar com uma em especial, que é voltada para a construção de uma cultura da paz nas escolas, o 
Conselho de Promoção da Cultura da Paz, que começa pela instituição de um conselho na escola, e que tem como objetivo geral promover e fortalecer relações de convivência solidária no ambiente escolar e na comunidade do entorno da escola.

O Grupo fornece uma cartilha onde mostra os passos principais para constituir um Conselho de Promoção da Cultura da Paz na escola, começando pela reunião de um grupo interessando em estruturar o conselho, e deliberação sobre os valores e princípios que irão nortear a ação do grupo, sua estrutura, composição e funcionamento e forma de deliberação, firmando desde logo que o Conselho não pode funcionar sem princípios como o do diálogo, e que a oportunidade de participação deve ser a mais geral possível, envolvendo toda a comunidade (inclusive as instituições que atuam no bairro), com todas as decisões por deliberação.

Como metodologia o Grupo propõe a vivência da Artemetodologia das Rodas de Abraços, que não é mais do que criar a oportunidade, o momento, de tentar reinventar novas formas de ver e sentir a prática da construção da paz, uma vivência partilhada das emoções que fazem parte da vida do ser humano, onde se desenvolve a capacidade de escutar o outro e de se expor, de partilhar medos e tristezas, histórias e experiências de vida na busca solidária de soluções, enfim, expandir a dimensão cuidante-amorosa na prática solidária dentro da escola.

E um pressuposto importante para o Grupo é que a violência na escola não tem como causa a ignorância dos conteúdos das matérias curriculares, e não é resolvida na discussão “conteúdos técnicos x conteúdos humanistas”, e nem em um passe de mágica, mas pode ser abordada de forma eficaz atacando a incapacidade de resolver problemas interpessoais e sociais de uma maneira inteligente.

\section{Considerações finais.}

De fato, o Grupo de Educação Continuada, por sua origem nos educadores que já pensavam a escola pública pela perspectiva da expansão da dimensão amorosa na escola e do exercício da cidadania como forma eficaz de religar o conhecer ao viver, como parte de um longo processo de amadurecimento da cultura escolar de uma escola de formação de professores que fez parte da história da educação no Amapá, apresenta credenciais suficientes para o desenvolvimento de um projeto capaz de mudar a feição da escola pública no Estado, e atacar diretamente o grave problema que se configura como uma bomba relógio armada com prazo de curto a médio, que é a evasão de sala de aula em massa do professor do ensino básico 
da escola pública, por absoluta falta de condições de prosseguimento do trabalho docente nos moldes em que é concebido hoje.

Essa evasão de professores da sala de aula geralmente se dá por esquiva, mediante alegação de problemas psicológicos causados pelo extremo estresse causado pela falta de segurança em todos os sentidos para o trabalho docente, seja em termos da falta de segurança pessoal ante as ameaças a vida do docente que tenta impor um mínimo de disciplina em sua sala de aula, seja em termos da falta de segurança didática que acomete fatalmente o professor que escreve num quadro e solicita aos seus alunos que copiem num caderno, quando esses alunos encontram tudo o que querem saber em um site de busca, pelo acesso ao mundo virtual, em uma lan-house, cujo mecanismo de acesso é acionado pelo pagamento em espécie, ou mesmo pelo aparelho que cabe em seu bolso.

Nesses termos, um projeto que pretende expandir a dimensão cuidante-amorosa na escola pública visando a cidadania, com base num referencial coerente, trabalhado por profissionais da educação confiantes na eficácia de seu projeto, certamente apresenta boas perspectivas de sucesso.

Entretanto, ainda que receba o Grupo todo o apoio político e administrativo que necessita para expandir se pensamento para os demais educadores da escola pública, e isso teria que acontecer em um programa bem mais amplo, que incluísse a atualização da escola para o nosso mundo real, digital e global, ainda restaria a contradição com as políticas públicas de saúde e segurança, que no Amapá são concebidas de forma completamente estanque em relação à escola pública.

O fato é que o fenômeno da sociabilidade violenta, que já não está restrito aos bairros pobres da Capital do Estado, mas alcança até os bairros de classe média, e que se espraia da baixada para a escola pública do seu entorno por suas representações, pode ser abordado e minimizado por um programa da natureza do desenvolvido pelo Grupo de Educação Continuada, mas, sem dúvida nenhuma, não deve a sociedade iludir-se na pretensão de que um problema tão complexo como esse seja resolvido tão facilmente.

O problema da naturalidade da agressão feita à escola pelo próprio aluno ou pela comunidade não se reduz à questão da pobreza ou da desigualdade social, e tampouco é resultado apenas da ausência do Estado, do crime organizado, ou do desenvolvimento de um Estado paralelo dirigido pelos criminosos nas áreas urbanas de extrema pobreza.

$\mathrm{Na}$ verdade, trata-se de uma nova forma de sociabilidade e que afeta muito mais profundamente as regiões urbanas mais concentradas e menos favorecidas: a instituição de 
uma ordem social norteada pela violência como princípio. E, sendo assim, pautada também na imprevisibilidade e na incerteza, posto que, sendo a violência não mais um meio, mas sim um princípio de afirmação de poder, ela surge indiscriminadamente, insensatamente, e imprevisivelmente, principalmente quando é usada exclusivamente como marcação de posição dentro dessa ordem.

Nessa condição, o assaltante mata sem que haja necessidade de matar, o político corrompe por hábito, o policial brutaliza sem que haja necessidade disso, e, consequentemente, o aluno agride a escola, os colegas ou o professor, sem que vejamos nisso qualquer sentido, porque estaremos olhando sob a perspectiva da outra ordem, a legal, e não a vigente na baixada, que é a pautada em outro princípio de sociabilidade, a violência.

Temos então por certo que, a despeito do respeitável referencial teórico utilizado pelo Grupo de Educação Continuada, e de sua prática educativa pautada na ampliação dos espaços de cidadania, garantindo assim bons resultados no trato com os problemas gravíssimos de evasão de alunos e de professores na escola pública, esse sucesso será sempre pontual e restrito, e, certamente, incerto nos casos de alunos, professores e escolas onde a violência já se tornou princípio de ordem.

Por fim, cabe observar que, embora o sonho dos professores do Grupo de Educação Continuada fosse a institucionalização de sua proposta como política pública, pela Secretaria de Educação do Estado, ao que tudo indica, a opção política vem sendo outra. De fato, a proposta não chamou atenção de nenhum dos grupos políticos que se alternam no governo do Amapá, e o que vemos hoje é a opção pelas Escolas Militares, apresentadas como ilhas de segurança, organização e sucesso escolar garantido, como a solução mais cômoda para o problema da violência nas escolas públicas do Estado do Amapá.

\section{Referências bibliográficas:}

AMAPÁ. Secretaria de Estado de Educação. Religando o Conhecer ao Viver - Revista de Educação Continuada, no 01 - SEED/AP. Avaliação: Mundos a Compartilhar. SET/2004.

Religando o Conhecer ao Viver - Revista de Educação Continuada, n ${ }^{\circ} \mathrm{o} 2-$ $\overline{\mathrm{SEED}} / \mathrm{AP}$. Ser Sendo Com o Coração na Totalidade. SET/2007.

BOLZAN, D. P. V.; POWACZUC, A. C. H. Docência Universitária: a construção da professoralidade. RBFP, ISSN 1984-5332 - Vol. 1, n. 3, p.90-104, Dezembro/2009.

CARVALHO, J. W. S. Instituto de Educação do Amapá: uma história de educação pelo exemplo. 2012. 220 p. Tese (Doutorado em Educação). Universidade Federal de Uberlândia, 2012. 
CHARTIER, R. A História Cultural: entre práticas e representações. Rio de Janeiro: Difel, Ed. Bertrand Russel, 1990.

JAPIASSU, H. \& MARCONDES, D. Dicionário de Filosofia. Rio: Zahar, 2001

LUCENA, Carlos. Relatório de Pós-doc apresentado à Universidade Federal de São Carlos, 2011 (Mimeo).

MATURANA, H.R. \& VARELA, F. J. A Árvore do Conhecimento: as bases biológicas da compreensão humana. São Paulo, Pala Athenas, 2001

MINAYO, M. C. de S. O desafio do conhecimento: Pesquisa qualitativa em saúde. $1^{\text {a }}$ ed. São Paulo: Hucitec-Abrasco, 1993.

Hermenêutica-dialética como caminho do pensamento social. In: MINAYO, M.C.S.; DESLANDES, S.F. Caminhos do pensamento: epistemologia e método. Rio de Janeiro: Ed. Fiocruz, 2002.

PORTO, J. L. R.; COSTA, M. A Área de Livre Comércio de Macapá e Santana: questões geoeconômicas. Macapá. O Dia S.A., 1999.

RABELO, M. G. L.; FERREIRA, N. R. IETA, Metodologia: construção, reconstrução e prática. 2001(mimeo).

SILVA, M. J. C. Gestão participativa, uma experiência vívida e vivida. (Mimeo), 2001.

SOUZA, O. A.; CORRÊA, E. Educação no IETA: Contexto histórico e Evolução. 2001 (Mimeo). 